\title{
DIÁLOGOS DA SOCIEDADE SOBRE A BIODIVERSIDADE BRASILEIRA NA RIO+20
}

A Sociedade Brasileira de Química participou da Conferência das Nações Unidas sobre Desenvolvimento Sustentável - Rio+20 em diversos eventos. Na grande mostra científica de projetos e ideias sustentáveis, realizada no Píer Mauá, mais de 50 instituições de ensino e pesquisa estiveram presentes no espaço "Armazém de Popularização da Ciência", ou simplesmente "Armazém Pop Ciência", desenvolvendo atividades sobre temas como sustentabilidade, reciclagem, produção de energia, diminuição da pobreza, meio ambiente e muitas atividades educacionais. A SBQ, com apoio de sua Secretaria Regional do Rio de Janeiro (SBQ-Rio), apresentou o experimento global $\mathrm{pH}$ da água do Planeta que, como sempre, foi um sucesso entre os estudantes e professores que visitaram o evento. Diversos kits para determinação do $\mathrm{pH}$ foram distribuídos para os professores que visitaram o espaço da SBQ e ficaram encantados com a ideia deste experimento global. Foram ainda realizados outros ensaios sobre a qualidade da água, especialmente com as escolas, e amplamente divulgadas as revistas QNEsc, QN, os portais QNINT e QUID+e a coleção de livros comemorativa do AIQ.

Ao se observar os projetos que foram apresentados nos quatros armazéns do Píer Mauá, pode-se constatar que o processo e as oportunidades para uma economia sustentável são reais. Certamente esses processos vão ser incorporados no dia-a-dia, independente das grandes decisões dos dirigentes e banqueiros mundiais, que só estão preocupados com quem vai pagar a conta de se passar de uma economia neoliberal para uma economia verdadeiramente sustentável.

Em um evento desse porte não poderiam deixar de ser discutidas as questões sobre a Biodiversidade, pois a cada ano 13 milhões de hectares de ecossistemas são perdidos em países tropicais e subtropicais, que abrigam a maioria das formas de vida do planeta. Recentemente, o Prof. Britaldo Silveira Soares Filho (UFMG) na sessão sobre Economia Verde da Reunião Magna 2012 da Academia Brasileira de Ciências disse: "As florestas têm mais valor em pé do que derrubadas. Quanto maior o desmatamento, mais cai a produtividade da soja, pois mudam-se os padrões climáticos". ${ }^{1}$

Muitas autoridades no assunto estiveram presentes na Rio+20, como o biólogo norte-americano Prof. Thomas Lovenjoy, da George Manson University, que relatou que continuam havendo perdas significativas de recursos naturais e que os cientistas falharam em mostrar que esse tema é importante. Em sua opinião, ele deveria estar dentro dos grandes temas que estão sendo discutidos pelos líderes mundiais, pois "transformar árvores em $\mathrm{CO}_{2}$ afeta soberania". No Brasil, a direção dos debates sobre a Biodiversidade caminhou na con- tramão das afirmações do eminente professor, pois nenhum país além do nosso partiu para discutir as metas de AICHI. ${ }^{2}$

No Parque dos Atletas ocorreu o evento "Construindo a Estratégia Brasileira Sobre a Biodiversidade para 2020", aberto à sociedade, onde o documento "20 Metas Brasileiras de Biodiversidade para 2020" (http://www.sbq.org.br/ PDF/20metasbiod2020.pdf) foi oficialmente entregue ao Dr. Roberto Cavalcanti (Secretário de Biodiversidade e Florestas, Ministério do Meio Ambiente). Participaram da mesa de debates Bráulio Dias (Secretário Executivo da CDB/ONU), Roberto Cavalcanti (Secretário de Biodiversidade e Florestas, MMA), Suzana Padua (Presidente, IPÊ - Instituto de Pesquisas Ecológicas), Maria Cecilia Wey de Brito (Secretária Executiva, WWF-Brasil) e Luiz Merico (Coordenador Nacional, UICN).

Tal documento foi resultado da iniciativa "Diálogos sobre Biodiversidade: construindo a estratégia brasileira para 2020" que envolveu 280 instituições, incluindo diversos setores da sociedade brasileira que propuseram as metas nacionais até 2020, seguindo as definições da Convenção de Diversidade Biológica de Nagoya (COP-10). A concepção do documento foi baseada na revisão e atualização da Estratégia e do Plano de Ação Nacional de Biodiversidade coordenado pelo Ministério do Meio Ambiente (MMA), WWF UICN - União Internacional para a Conservação da Natureza, WWF-Brasil e Instituto de Pesquisas Ecológicas (IPÊ). Esse trabalho levou cerca de 2 anos para ser concluído e visou integrar a sociedade como um todo na agenda da Biodiversidade do Brasil com as metas de AICHI.

Não há conhecimento que outro país tenha realizado um documento similar com tão ampla participação da sociedade. Foram 12 reuniões setoriais, consulta pública via web, duas reuniões finais, 517 submetas propostas, 150 contribuições e 2 publicações. ${ }^{2,3}$ Em relação às metas, 13 tiveram consenso, 5 consenso parcial e 2 com mais de uma contribuição. $\mathrm{O}$ apoio financeiro para este trabalho veio do Ministério do Meio Ambiente, Alimentação e Assuntos Rurais do Reino Unido (Defra) e do Projeto Nacional de Ações Integradas Público-Privadas para Biodiversidade (Probio II).

O documento que foi entregue ao Ministério do Meio Ambiente é a base de um trabalho mais intenso que não se encerra em si mesmo, pois o Brasil, como detentor da maior Biodiversidade do planeta, deveria continuar dando exemplos positivos na sua conservação e, portanto, é imperativo que transformem essas 20 metas em políticas e instrumentos do governo. 
Não há uma instituição sozinha capaz de levar adiante essas metas. Novamente tem que haver participação de diversas instituições sob a coordenação do Ministério do Meio Ambiente para articular, monitorar e mobilizar recursos financeiros para que os projetos sejam executados com transparência, respeito à diversidade cultural e ambiental, ampla participação e controle da sociedade.

No que diz respeito às articulações dentro do governo, o Ministério do Meio Ambiente (MMA) encaminhou as metas à Comissão Nacional da Biodiversidade (Conabio), órgão consultivo do MMA, que decidiu em 27/04/2012 apoiar e validar as metas nacionais de biodiversidade a serem implantadas até 2020, e que integram os Diálogos de Biodiversidade: Construindo a Estratégia Brasileira para 2020.

A nossa Biodiversidade precisa ser aproveitada e explorada racionalmente para que possa gerar riquezas para os brasileiros e a Química pode ter grande participação nesse processo. $\mathrm{O}$ seu estudo químico, bioquímico e biotecnológico é o campo de trabalho de centenas de Químicos que se interessam na conservação da Biodiversidade e apoiam quaisquer metas que visem a proteção da nossa Biodiversidade. As plantas sempre foram objetos do uso e estudo pelo Homem e se constituem em uma fonte imensa de novos produtos naturais que se tornam fármacos, ou de substâncias bioativas que são modelo para a síntese de protótipos de fármacos ou mesmo medicamentos. Sugerimos estender essa meta para outras aplicações, a exemplo de inseticidas naturais, corantes alimentícios, aromatizantes, entre outros. Isso nos orgulha muito. Porém, junto com essas metas devem ser estabelecidas políticas científicas que permitam aos cientistas brasileiros o acesso a essa Biodiversidade sem as burocracias atuais ou punições, como se fossem bandidos. ${ }^{4}$ A trava que se colocou no sistema, ao invés de fomentar a curiosidade, está diminuindo uma geração de novos doutores interessados na área de produtos naturais. Será lamentável se no futuro tivermos que importar cientistas de outros países para trabalhar em Química dos Produtos Naturais, que no passado foi uma das áreas mais importantes da Química brasileira.

A Sociedade Brasileira de Química tem sido parceira e se posiciona em favor da conservação da Biodiversidade com o "compromisso incondicional de trabalhar em conjunto para um futuro próspero, sem fome ou pobreza, igualitário, com tolerância étnica, religiosa, seguro e com desenvolvimento sustentável para preservar a vida e o planeta". ${ }^{5}$

Susana I. Córdoba de Torresi

Vera L. Pardini

Vitor F. Ferreira

Editores de QN

\section{REFERÊNCIAS}

1. http://www.abc.org.br/impressao.php3?id_article $=2014$, acessada em Maio 2012.

2. http://www.graduacao.univasf.edu.br/biologia/arquivos/metas_de_aichi_ situacao_atual_no_brasil__2011_download.pdf, acessada em Junho 2012.

3. http://d3nehc6y19qzo4.cloudfront.net/downloads/livro_verde_da biodiversidade_2011_1.pdf, acessada em Junho 2012.

4. Ferreira, V. F.; Quim. Nova 2000, 23, 579.

5. Ferreira, V. F.; J. Braz. Chem. Soc. 2012, 23, 793. 